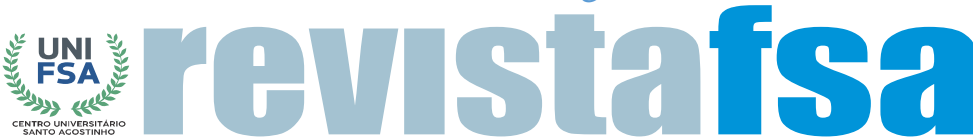 \\ www4.fsanet.com.br/revista
}

Rev. FSA, Teresina, v. 18, n. 04, art. 8, p. 144-158, abr. 2021 ISSN Impresso: 1806-6356 ISSN Eletrônico: 2317-2983 http://dx.doi.org/10.12819/2021.18.04.8

\section{Avaliação da TPM como Ferramenta de Melhoria no Desempenho da Produção: Um Estudo de Caso}

TPM Evaluation as a Tool for Improving Production Performance: A Case Study

Jordanna de Souza Camargo Graduada em Engenharia de Produção pela Universidade Federal de Catalão

E-mail: jooscamargo@gmail.com

André Alves de Resende Doutor em Engenharia Mecânica pela Universidade Federal de Uberlândia Professor na Universidade Federal de Catalão

E-mail: aaresende@gmail.com

Endereço: Jordanna de Souza Camargo

Av. Dr. Lamartine Pinto de Avelar, 1120. Setor Universitário - CEP: 75704-020. Catalão-GO. Brasil. Endereço: André Alves de Resende

Av. Dr. Lamartine Pinto de Avelar, 1120. Setor Universitário - CEP: 75704-020. Catalão-GO. Brasil.
Editor-Chefe: Dr. Tonny Kerley de Alencar Rodrigues

Artigo recebido em 25/03/2021. Última versão recebida em 01/04/2021. Aprovado em 02/04/2021.

Avaliado pelo sistema Triple Review: a) Desk Review pelo Editor-Chefe; e b) Double Blind Review (avaliação cega por dois avaliadores da área).

Revisão: Gramatical, Normativa e de Formatação 


\title{
RESUMO
}

A Manutenção Produtiva Total (TPM) envolve produção e manutenção de forma eficiente e eficaz para garantir a produção conforme a programação. Neste contexto, o objetivo desse artigo é analisar os cenários anterior e posterior à aplicação da ferramenta em uma indústria automobilística. Foi identificado que a implementação da TPM exigiu baixos investimentos e apresentou resultados em pouco tempo. O setor observado foi a área de solda. Como resultado foi observada uma redução de $87,78 \%$ na manutenção corretiva não planejada e uma média das paradas não programadas 20 vezes inferior ao observado anteriormente. Conclui-se que a TPM, e em particular a manutenção preventiva, pode beneficiar a disponibilidade e a confiabilidade do processo, assim como aumentar a eficiência da manutenção como fator estratégico.

Palavras-chave: TPM. Disponibilidade. Confiabilidade. Parada. Desempenho.

\begin{abstract}
Total Productive Maintenance (TPM) involves production and maintenance efficiently and effectively to guarantee production according to schedule. In this context, the objective of this article is to analyze the scenarios before and after the application of the tool in an automobile industry. It was identified that the implementation of the TPM required low investments and presented results in a short time. The sector observed was the welding area. As a result, a reduction of $87.78 \%$ was observed in unplanned corrective maintenance and an average of unscheduled stops 20 times lower than previously observed. It is concluded that TPM, and in particular preventive maintenance, can benefit the availability and reliability of the process, as well as increase the efficiency of maintenance as a strategic factor.
\end{abstract}

Keywords: TPM. Availability. Reliability. Stop. Performance. 


\section{INTRODUÇÃO}

No decorrer da história, entre as etapas da constituição do setor automobilístico, destaca-se a criação do primeiro carro experimental em 1903, por Henry Ford. O modelo vendeu 1.708 unidades, e os conceitos utilizados na linha de produção revolucionaram o mundo. Onze anos depois (1914), os irmãos Dodge desenvolverama sua própria indústria automobilística, com o diferencial de a carroceria ser toda em aço, e 70.700 unidades foram vendidas (MENDES et al. 2017).

Em um progresso natural, o desenvolvimento no segmento automotivo resultou na busca por técnicas que pudessem representar um diferencial competitivo e consequentemente a fidelização de clientes (JIPM, 2008). No Brasil, o processo não foi diferente. A partir da abertura econômica no início dos anos 90, novos investimentos e indústrias começaram a ser instalados e melhorias no setor produtivoforam implantadas.

Nesse contexto, os equipamentos e as metodologias de manufatura passam aser mais sofisticados para conseguir atingir um maior volume de produção e com maior previsibilidade de tempos (SINGH, 2014). Essa combinação do cumprimento da produção programada com a automação dos equipamentos fez-se indispensável para a melhoria do gerenciamento da manutenção dos equipamentos a fim de garantir a qualidade da produção (SLACK, 2002). Assim, surge o método de gestão Total Produtive Maintenance (TPM), termo difundido no Brasil como Manutenção ProdutivaTotal.

Um dos principais objetivos da TPM é, por meio de uma manutenção planejada e programada, promover a eliminação das causas de quebra e dos defeitos dos equipamentos. Essa ferramenta se baseia no comportamento humano e compreendeque a operação correta, manutenção eficiente de equipamentos e máquinas, contribuina melhoria da produtividade, custos de produção baixos, preços competitivos e qualidade de serviço (MONTEIRO, 2012).

Para Tondato (2004), os aumentos da eficiência decorrentes da implementação da TPM têm oscilado entre 60 e 90\% em indústrias japonesas. Nuci (2014) por sua vez retrata sobre uma indústria de embalagens de papelão ondulado que obteve um aumento na capacidade de produção de $11,60 \%$, uma redução de 78,33\% em relação às quebras, totalizando um rendimento anual $25 \%$ maior que o ano anterior.

Por sua vez, a disponibilidade e a confiabilidade dos equipamentos são essenciais para a garantia de erros menos constantes através de um processo de prevenção a falha (NETTO, 2008). Desse modo, faz-se uso de indicadores para auxiliar a gestão da operação junto aos objetivos da organização. Assim, os processos, quando alterados, necessitam de 
um monitoramento dos resultados, para que seja possível mensurar o impacto sobre as demais áreas e indicadores, objetivando a eficácia e a eficiência dos processos da organização (PACHECO; MATINS, 2015).

Assim, este artigo tem por objetivo avaliar, em uma indústria automobilística, os cenários anterior e posterior à implementação da TPM no período de janeiro de 2018 a dezembro de 2019. Os resultados serão medidos por meio de indicadores de manutenção e os benefícios apresentados.

O presente artigo justifica-se por evidenciar na prática como a implementação estruturada da Manutenção Produtiva Total influencia positivamente nos indicadores de manutenção e resultados da empresa. Também servirá de referência para outras áreas da empresa compreender como a ferramenta é capaz de melhorar os resultados do setor.

\section{REFERENCIAL TEÓRICO}

A partir do século XVII, com o avanço tecnológico, a manutenção surge como uma necessidade das indústrias para manterem os equipamentos em funcionamento. Posteriormente, no século XVIII, com a Revolução Industrial, as tecnologias evoluíram de forma rápida, aumentando ainda mais a necessidade de atividades de conserto e conservação dos equipamentos (BIEHL; SELLITO, 2015).

Por sua vez, apenas na década de 50 do século XX, nos Estados Unidos, o termo manutenção passa a ser difundido (NETTO, 2008). Nesse período pós-guerra, fez-se necessária a divisão da área da manutenção da produção para que melhorasse o desempenho do sistema produtivo, já que se tratava de uma época de desenvolvimento tecnológico.

\subsection{Manutenção corretiva não planejada}

Para Santos (2013, p. 13), a manutenção corretiva não planejada representou o princípio em que o operador basicamente conserta o que está quebrado, não se preocupando com as causas ou os efeitos que ocasionaram o defeito.

Segundo Kardec e Nascif (2012, p. 39), esse tipo de atuação trabalha com o intuito da correção da falha de maneira aleatória, ou seja, a atuação operacional trabalha diretamente no fato já ocorrido. Essa circunstância comumente gera altos custos, visto que a quebra inesperada pode ocasionar elevados custos indiretos na manutenção, diminuição na qualidade do produto, danos no processo, assim como danificar o equipamento. 


\subsection{Manutenção Corretiva Planejada}

Para Takahashi e Osada (1993, p.177), esse tipo de manutenção trabalha no reparo programado das avarias detectadas durante as inspeções preventivas ou preditivas, assim como os reparos que tornam o equipamento mais fácil para inspecionar e mais confiável. Essa política executa atividades como melhoria em sistemas de segurança, aperfeiçoamento no sistema de lubrificação, redução nos riscos de acidente e eliminação de agentes de contaminação.

Kardec e Nascif (2012, p. 58) destacam que a característica principal da manutenção corretiva planejada é a função da qualidade de informação fornecida peloacompanhamento do equipamento. Nota-se, portanto, que a maior vantagem da manutenção planejada sobre a não planejada se deve à disponibilidade do equipamento, já que o acompanhamento das variáveis torna possível que o reparo ocorra de forma planejada.

\subsection{Manutenção Preventiva}

Costa (2013) afirma que as atuações com manutenção preventiva juntamente com a corretiva não planejada exercem majoritariamente o percentual de atividades executadas nas empresas no Brasil. Segundo Kardec e Nascif (2012, p. 43), manutenção preventiva é baseada em intervalos de tempo, de forma a reduzir a queda no desempenho e evitar falhas conforme um plano previamente elaborado. Esse plano de trabalho é feito a partir das informações do fabricante, do conhecimento técnico e do relatório histórico do equipamento.

Yoshicazem (2002), contudo, ressalta a relevância deste já que o aperfeiçoamento das técnicas existentes na manutenção preventiva deu origem ao TPM, objetivando a falha zero dos processos, dos equipamentos e redução de perda. Por sua vez, a manutenção planejada é um dos 8 pilares da Manutenção Produtiva Total.

\subsection{Manutenção produtiva total}

A formulação e a implementação de estratégias baseadas na manutenção produtiva total (TPM) resultam em um aumento eminente no desempenho da manutenção (SIGH, 2014). Segundo Monteiro (2012), as atividades dessa ferramentaconcentram em melhorias do ativo industrial, com preços competitivos, custos de produção baixos e equipe de produção 
focada e motivada nos resultados a fim de minimizar avarias, abordar o ciclo de vida dos equipamentos, acidentes com danos patrimoniais e pessoais e defeitos de produção.

Bielh (2015) retrata que, para que se consigam atingir os objetivos da eficiência máxima da ferramenta, é necessário que se elimine tudo que reduza a eficácia, ou seja, as perdas. As principais perdas que devem ser extintas são classificas para Nuci (2015) como: queda de rendimento noturno, refugos e retrabalhos, tempos de espera, tempo de setup e quebras.

Para que se consiga evitá-las, Carrijo (2008) apresenta os 8 pilares da TPM em: manutenção autônoma; melhorias específicas; manutenção planejada; manutenção de qualidade; segurança, saúde e meio ambiente; educação e treinamento; melhoria dos processos administrativos.

\subsection{Indicador de disponibilidade}

Moraes (2014) define o indicador de disponibilidade como sendo um dos principais objetivos da gestão da manutenção. Ele é caracterizado pelo período em que a máquina está disponível para funcionamento conforme o programado, logo quanto maior for esse percentual melhor. O índice pode ser encontrado a partir da Equação (1):

$$
D(\%)=\frac{T P-P P-P N P}{T P-P P}
$$

Sendo que a unidade utilizada foi horas, em que TP é o tempo total programadocom base na demanda da produção; PP são as paradas planejadas, ou seja, intervalos para almoço, reuniões e manutenção planejada; e PNP são as paradas não planejadas, como manutenção de emergência.

\subsection{Indicador de confiabilidade}

Na gestão da Manutenção, a confiabilidade pode ser definida como a probabilidade de desempenho adequado, em um determinado período de tempo, por sistemas, cadeias produtivas e máquinas. Essa pode ser realizada através do histórico de funcionamento dos equipamentos e de sua estimativa de atividades futuras(LOPES, 2017).

$$
C=e^{-\lambda \mathrm{r}}
$$


Em que $\lambda$ se trata da taxa de falha, ou seja, o inverso do tempo médio entre falhas (MTBF) e t o tempo em horas de projeção que deseja analisar.

\section{METODOLOGIA}

O estudo de caso foi realizado por meio da análise dos indicadores de performance das horas de atendimentos às manutenções preventivas e corretivas, indicadores de disponibilidade e confiabilidade, averiguando a frequência com que as paradas indesejadas ocorriam e quais suas possíveis consequências.

Os dados apresentados foram coletados através dos registros gerados pelo histórico da empresa, por meio do software Engeman, ordem de serviço manual, ordem de serviço sistêmica e help desk, que são os documentos oficiais de input no software que podem ser convertidos para planilhas do Excel. O intervalo de análise foi de 24 meses (compreendido de janeiro de 2018 a dezembro de 2019). O setor analisado foi o de solda, sendo divididas suas linhas de produção em Solda de Cabine, Solda de Carroceria, Fechamento de Portas e Acabamento de Cabine.

A averiguação e o estudo dos dados coletados foram divididos em dois momentos. $\mathrm{O}$ primeiro consiste na análise anterior à implementação da TPM de janeiro a dezembro de 2018, e o segundo, consequentemente, no pós-implantação dejaneiro a dezembro de 2019. Para ambos, foi realizada a seguinte sequência de tarefas:

1. Indicador de Distribuição das Atividades: obtenção no banco de dados da empresa, analisando os percentuais do total das horas realizadas pela manutenção;

2. Indicadores de Paradas: obtenção no banco de dados da empresa,analisando a quantidade de paradas acumulativas em cada mês;

3. Indicadores de Confiabilidade e Disponibilidade: obtenção das informações através do software Engeman, utilizado pela empresa;

4. Avaliação e analise dos indicadores através das informações coletadas anteriormente;

É importante evidenciar que essas etapas foram realizadas para ambos os períodos de análise, portanto a coleta de dados e a aplicação dos indicadores foram executadas de forma análoga para os dois momentos. 


\section{RESULTADOS E DISCUSSÕES}

Para uma melhor visualização e interpretação dos resultados, eles serão dispostos em forma de gráfico. Os dados de 2018 se referem ao período anterior à implementação, e os dados de 2019 se referem ao período após a implementação daTPM.

\subsection{Indicador de distribuição de atividades}

Esse indicador foi responsável por mensurar os resultados dos percentuais das atividades executadas pela manutenção. O gráfico mostra a distribuição da manutenção preventiva, a manutenção corretiva não planejada, a manutenção corretiva programada, as instalações e outros serviços. A Figura 1 apresenta os resultados percentuais das atividades executadas pela manutenção antes da implementação da TPM (ano de 2018).

\section{Figura 1 - Distribuição das atividades de manutenção anterior à implementação da TPM (ano de2018)}

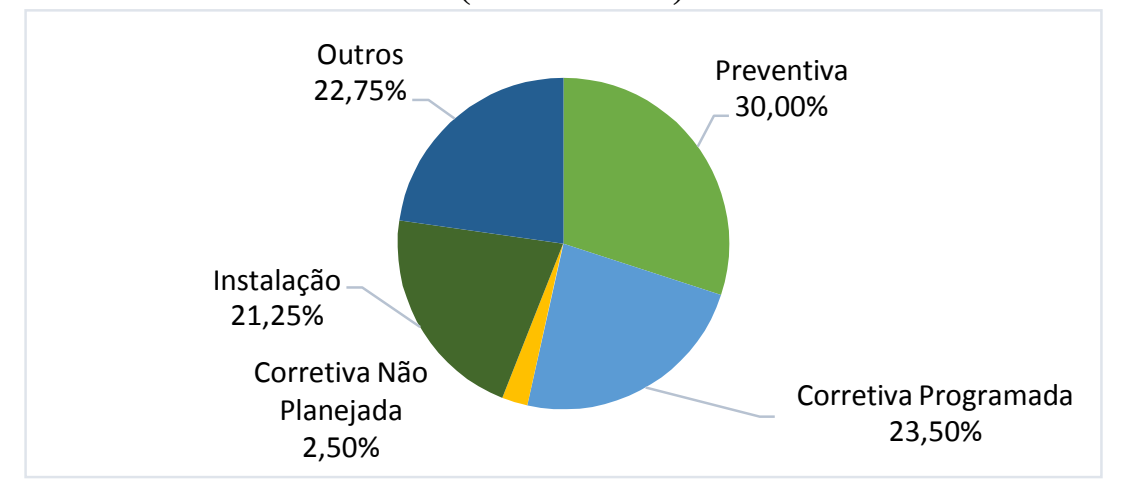

Fonte: Elaborado pelos autores (2020)

Ao analisar o gráfico, foi constatado um número alto de execução de tarefas necessárias, mas que não agregavam valor às atividades da manutenção, sendo estas classificadas como Outros Serviços. Este representa 22,75\% do total anual, entre Shutdowns, preenchimento de Ordens de Serviço, Start Up, deslocamento para operação, deslocamento com ferramentas e materiais e acompanhamento da manutenção. As Instalações correspondem a $21,25 \%$ e são atendidas tanto equipamentos de produção como necessidades não vinculadas a esta.

As Manutenções Corretivas Programadas somaram um valor de 23,5\% do total dos chamados da manutenção, resultante do número de preventivas comnecessidades de spare parts e ocupações originárias das corretivas imediatas. Açõespreventivas resultaram $30 \%$ das 
atividades totais realizadas na manutenção, distribuídas entre mecânica, elétrica, limpeza e lubrificação. Por fim, com $2,5 \%$ está a manutenção corretiva não planejada, que são intervenções que diminuem a confiabilidade do processo e aumentam os custos de produção.

$\mathrm{Na}$ Figura 2, estão representadas as distribuições das atividades posteriores à implementação da Manutenção Produtiva Total durante os meses de janeiro a dezembro no ano de 2019. A partir desse gráfico, será possível identificar as melhorias promovidas pela TPM.

\section{Figura 2 - Distribuição das atividades de manutenção após a implementação da TPM (ano de 2019)}

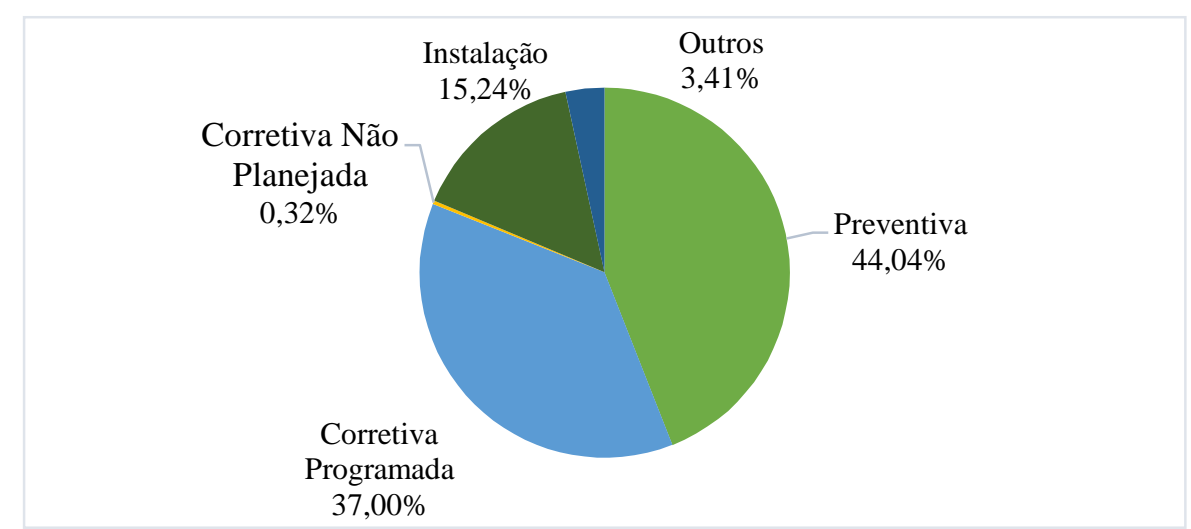

Fonte: Elaborado pelos autores (2020).

As iniciativas focadas em reestruturação do departamento de manutenção com a implementação da TPM na fábrica resultaram na diminuição das atividades que não agregavam valor, definida anteriormente como Outros, de 22,75\% para 3,41\%. Resultado conveniente com o que foi retratado por Bielh (2015), enfatizando-se que, com a execução da Manutenção Produtiva Total, tende-se a eliminar tudo que reduza a eficácia para que se atinjam os objetivos com eficiência. Esse efeito repercute diretamente na redistribuição de tarefa em atividades essenciais, decorrendo, por exemplo, no aumento percentual do total das preventivas realizadas de $30 \%$ para 44,04\% com relação aos seus respectivos períodos.

As corretivas programadas que necessitam de intervenção, seja ela após uma correção preventiva ou imediata, sofre um aumento como um reflexo positivo das mudanças geradas. As corretivas não planejadas para o período de 2019 foram abaixo de $1 \%$ de ocorrências, tendo redução de 87,78\% com relação a 2018. Ambas as alterações refletem em disponibilidade e confiabilidade de equipamento e desempenho técnico, conforme afirmado por Kardec e Nascif (2012). 


\subsection{Indicador de Parada}

Na figura 3, são apresentados os dados de parada acumulada mensalmente para os anos de 2018 e 2019. O Indicador de parada foi responsável pelo parâmetro em horas do período de tempo em que o setor da solda ficou sem execução de atividades. Por conseguinte, essa falha é um grande gerador de perdas na produtividade, confiabilidade e disponibilidade do processo. Logo, quanto menor for esse período de tempo com paradas, melhor será a eficácia do sistema produtivo. Isso se deve porque as fórmulas de disponibilidade e confiabilidade são diretamente afetadas pela quantidade e frequência de paradas.

\section{Figura 3 - Relação do Indicador de parada anterior e pós a implementação da TPM (ano de 2018 -2019)}

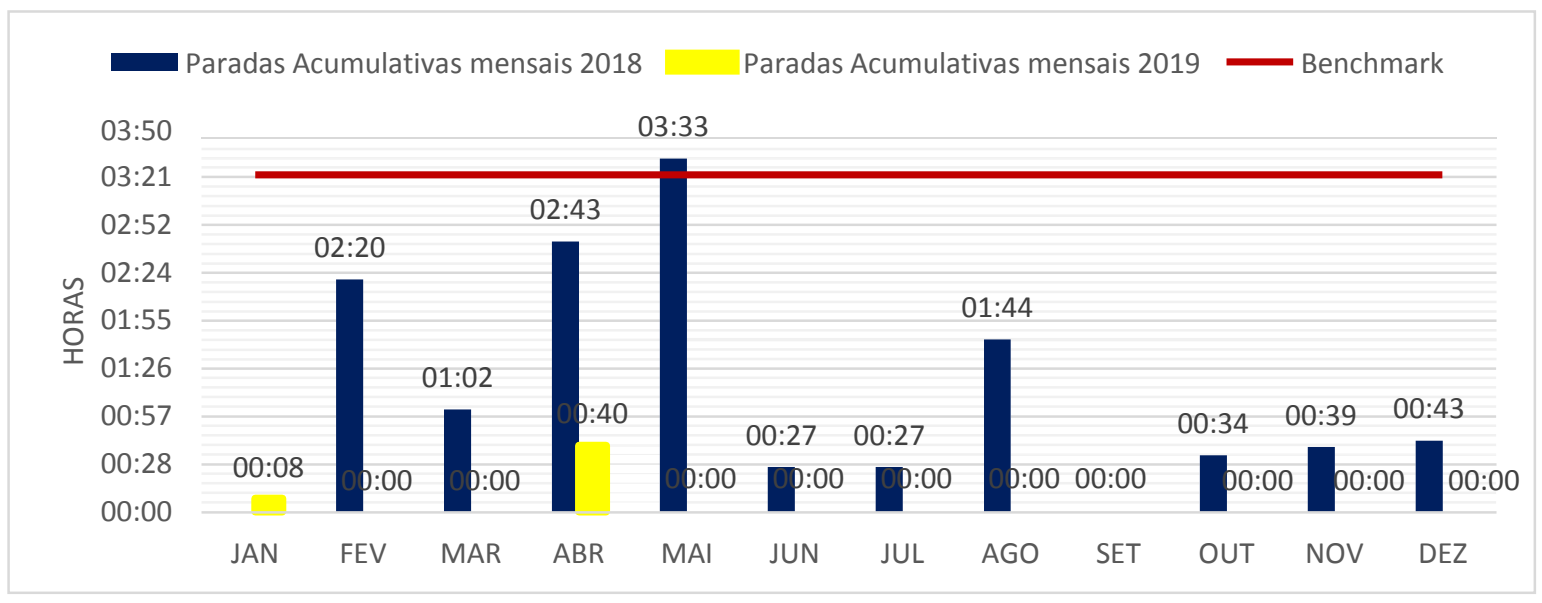

Fonte: Elaborado pelos autores (2020)

No primeiro mês de 2018, é possível visualizar que o somatório resultou em zero, decorrente das férias coletivas que a empresa situava. $\mathrm{O}$ valor do benchmark jáhavia sido pré-estabelecido anteriormente e foi fornecido pela empresa em análise, sendo de 3:23 horas. Nota-se uma variação alta durante o período anterior à implementação da ferramenta, destacando o mês de maio, em que o indicador apresenta um valor superior ao limite estipulado.

Posteriormente, em 2019, é notória a mudança de comportamento já com a implementação da Manutenção Produtiva Total, em que a variação de tempo de paradas acumulativas foi significantemente inferior à do ano anterior. Ressalta-se que o valor limite do benchmark não foi alterado de um ano para o outro. Comparando os dois anos das interrupções ocorridas, em 2019 teve uma redução nas paradas de 94,36\%. Observa-se uma 
relação prática do aumento das atividades da Manutenção Preventiva Total com a redução das paradas e consequentemente perdas geradas por estas em concordância com o afirmado por Costa (2013).

\subsection{Indicador de Disponibilidade}

A disponibilidade, como ressaltado anteriormente, é essencial no planejamento da gestão da manutenção, afinal ela é responsável pelo tempo em que o maquinário está em estado operacional ou alinhado para solicitações de trabalho. Dessa forma, a falta de planejamento é causa de manutenções desorganizadas e indisponibilidades na produção. $\mathrm{Na}$ figura 4 a seguir, é possível visualizar as variações desse indicador.

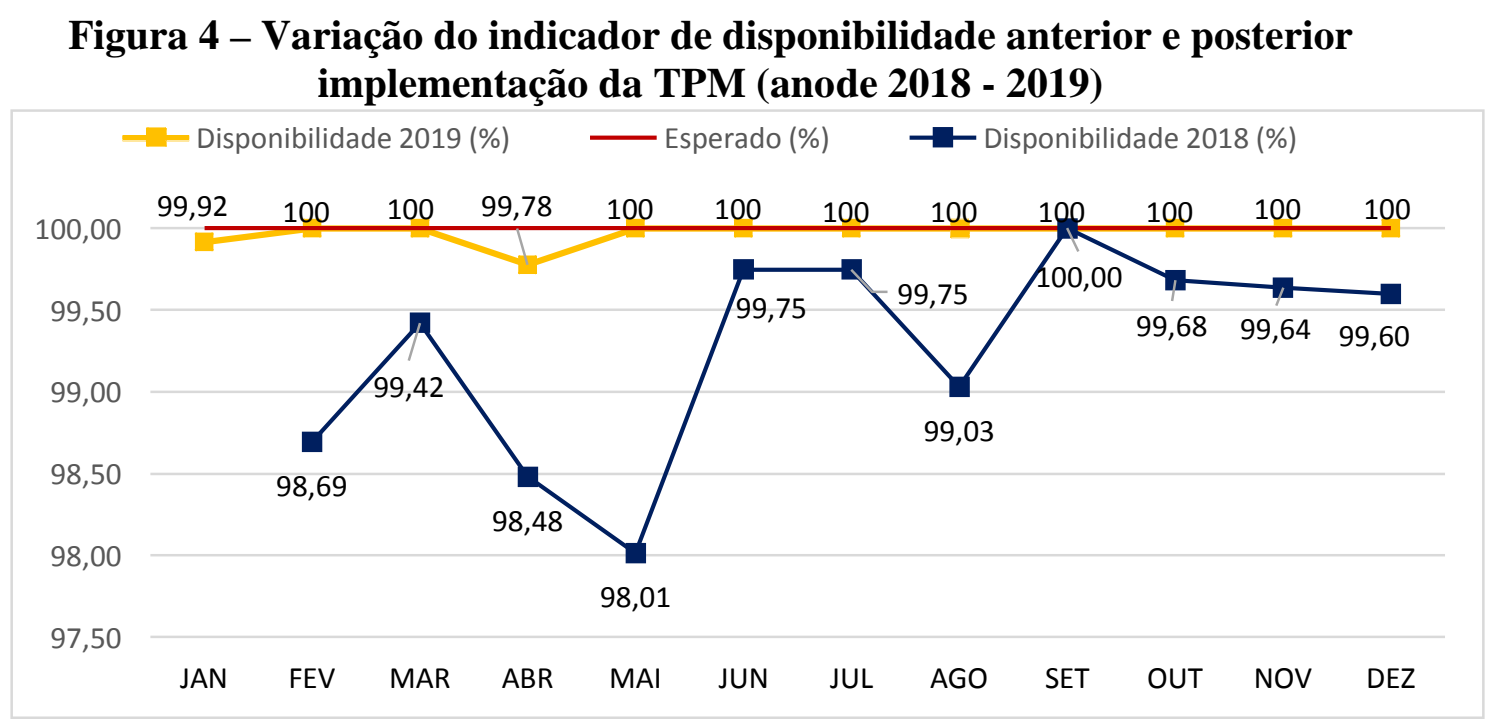

Fonte: Elaborado pelos autores (2020)

Há variações significativas no decorrer do ano de 2018, chegando à baixa de 98,01\% . Essas avarias foram causadas por problemas como falta de peças, tempo delocomoção da identificação do problema até o conserto do equipamento, falta de ferramenta, limpeza e necessidade de adaptação. Conforme citado, Takahashi e Osada (1993) afirmam que esse tipo de falha pode ser identificado durante as inspeções preventivas ou preditivas.

Em concordância com a relevante diminuição da Manutenção Não Programada e o aumento da Manutenção Programada, gerou-se uma crescente notável na disponibilidade dos equipamentos e estabilidade do indicador. Esse fator se dá em razão de o acompanhamento das alterações e o reparo serem executados pós-horário produtivo e a qualidade dos dados 
operacionais passarem a ser mais precisos quando acompanhados diariamente, conforme evidenciado por Kardec e Nascif (2012).

\subsection{Indicador de confiabilidade}

Sob as condições expostas, o comparativo a partir do indicador de confiabilidade será fundamental. Ele servirá para mensurar a probabilidade do setor executar suas atividades sem falhas, conforme elucidado a seguir.

\section{Figura 5 - Relação do indicador de confiabilidade do período anterior e pós a implementação da TPM(ano de 2018 - 2019)}

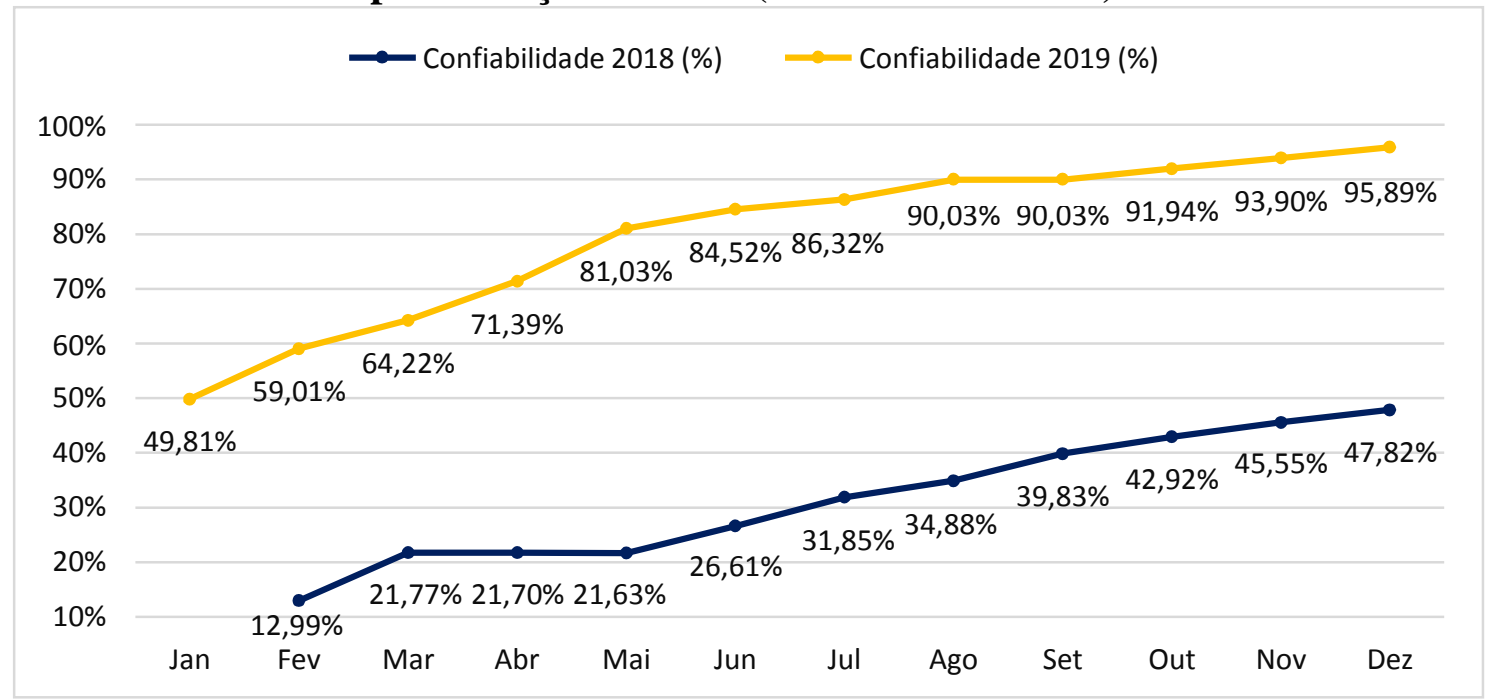

Fonte: Elaborado pelos autores (2020)

Exceto em janeiro de 2018 em que houve férias coletivas, em ambos os anos foram trabalhadas 180 horas semanais e a projeção utilizada para calcular o indicador de confiabilidade de cada mês foi de 45 horas. Ainda em 2018, no mês fevereiro, o indicador apresentou uma probabilidade do setor de solda funcionar conforme suas especificações de apenas $12,99 \%$ e uma máxima em dezembro de 47,82\%. Nota-se uma crescente probabilística devido à diminuição de frequência de falhas no decorrer do ano. Isso se dá devido à confiabilidade se tratar de um indicador acumulativo. Contudo, essa crescente é muito mais acentuada no ano de 2019 já que teve apenas duas falhas, contrário ao ano de 2018 com 32 pausas.

Quando comparados os desempenhos da disponibilidade e da confiabilidade no mesmo período de 2018, percebe-se um comportamento comum de instabilidade, causador de falhas e perdas no processo produtivo, reação já sustentada anteriormente por Netto (2008). 
É relevante salientar que, durante esse ano com grandes oscilações, também há um percentual alto de atividades nomeadas como Outros, assim como Instalações e Manutenção Corretiva Não Planejada.

Contrário ao ano anterior, o indicador em 2019 apresentou uma atuação estável no decorrer dos meses, exibindo uma variação, exclusivamente nos meses de janeiro e abril, sendo que mantiveram às 180 horas trabalhadas mensais. Ao comparar os comportamentos entre 2018 e 2019, com a redistribuição das atividades da manutenção, salienta-se uma reação já expressa por Monteiro (2012), que, ao empregar-se a TPM, garantindo uma manutenção planejada e compromisso humanoconivente, manifesta a diminuição de falhas, aumento da qualidade no processo e melhoria na produtividade.

\section{CONSIDERAÇÕES FINAIS}

O objetivo desse artigo foi explorar, através de indicadores de desempenho, como a inserção da Manutenção Produtiva Total repercute durante o processo produtivo em uma indústria automobilística. A questão do trabalho foi respondida por meio de uma avaliação de cenários no decorrer de janeiro a dezembro de 2018 e posteriormente, de janeiro a dezembro de 2019, que corresponde ao período anterior e posterior à implementação da ferramenta.

Ressalta-se a importância deste trabalho por sua compreensão e aprofundamento no tema da Manutenção Produtiva Total de forma prática. Através dele, foi possível visualizar a relevância do envolvimento de toda pirâmide hierárquica na disseminação do conhecimento e boas práticas para a geração da manutenção autônoma e performance satisfatória, assim como avaliar o emprego da Engenheira de Produção na melhora do desempenho produtivo e análise dos resultados, por meiode uma ferramenta simples e atestada eficaz.

Por sua vez, os objetivos projetados inicialmente foram alcançados como evidenciado na análise dos resultados. Os principais desfechos foram a diminuição das atividades que não agregavam valor - mas que são necessárias - de 22,75\% para 3,41\%, repercutindo na redistribuição das tarefas essenciais como o aumento percentual do total das preventivas de $30 \%$ para $44,04 \%$. Outro ponto a ser evidenciado é que, com a utilização da TPM, houve a redução de $87,78 \%$ das atividades corretivas imediatas e de $94,36 \%$ nas paradas indesejadas comparado aoano anterior, refletindo positivamente nos indicadores de disponibilidade e confiabilidade. 
Logo se constata que a TPM pode ser utilizada como um fator estratégico por ter-se mostrado eficiente nas atividades da manutenção e consequentemente podendo gerar um processo produtivo mais competitivo. Tem-se, contudo, como sugestão, a análise das reduções de defeitos nos produtos fabricados posterior à implementação da ferramenta, já que a redução de quebras de máquinas e o aumento na confiabilidade podem ter gerado reflexos como a ampliação na qualidade do produto.

\section{REFERÊNCIAS}

BIEHL, N. C; SELLITTO, M. A. TPM e manutenção autônoma: estudo de caso em uma empresa da indústria metal- mecânica. Manutenção Produtiva Total, Revista Cientifica Eletrônica de Engenhariade Produção, 2015. Disponível em: producaoonline.org.br. Acesso em: 8 out. 2019.

CARRIJO, J. R. S. Adaptações do modelo de referência do Total Productive Maintenance para empresas brasileiras. Tese apresentada ao Programa de Pós Graduação em Engenharia de Produção. Faculdade de Engenharia Arquitetura e Urbanismo da Universidade Metodista de Piracicaba. Santa Bárbara doOeste, 2008.

COSTA, M. A. - Gestão estratégica de manutenção: uma oportunidade para melhorar o resultado operacional. 2013. 103 f. Trabalho de conclusão de curso(Graduação em Engenharia de Produção) -Universidade Federal de Juiz de Fora, Juizde Fora, 2013.

JIPM. Japan Institute of Plant Maintenance Solutions Companhy Limited. JIPM-S. Disponível em: www.jipm.or.jp/en/home Acesso em: 10 out. 2019

KARDEC, A; NASCIF, J. Manutençao: Função Estratégica. 4º ed. rev. Qualitymark, 2012.

LOPES, N. R. Implantação do indicador overall equipment effectiveness (oee) numa empresa da indústria alimentícia. Overall Equipment Effectiveness, ENCONTRO NACIONAL DEENGENHARIA DE PRODUCAO, 2017.

MENDES, C. R; SIEMON, F. B; CAMPOS, M. M. Estudos de caso da indústria 4.0 aplicados em uma empresa automobilística. Indústria Automobilística 4.0, POSGERE, 2017.

MONTEIRO, A.; MONTEIRO, D.; MOTTA, D.; SILVA, D. Proposta de aumento de eficiência fabril por meio da manutenção produtiva total em uma empresa fabricante de embalagem de alumínio. ENCONTRO NACIONAL DE ENGENHARIA DE PRODUÇÃO. Anais.. Bento Gonçalves: ABEPRO, 2012. 
NUCI, R. C. Implantação da metodologia tpm em uma indústria de embalagens de papelão ondulado. Gestão da Manutenção, Universidade São Francisco, 2 dez. 2015. Disponível em: lyceumonline.usf.edu.br. Acesso em: 22 out. 2019.

NETTO, W. A. C. A importância e a aplicabilidade da manutenção produtiva total (TPM) nas indústrias. ManutençãoProdutiva Total, UNIVERSIDADE FEDERAL DE JUIZ DE FORA, 2008.

PACHECO, D. A. J; MARTINS, M. Análise da sistemática de gestão dos indicadores de desempenho na indústria automotiva.Gestão dos Indicadores, Revista Ingeniería Indústrial, 2015.

SLACK, N.; CHAMBERS, S.; JOHNSTON, R. Administração da Produção. São Paulo: Atlas, 2002.

TAKAHASHI, Y; OSADA, T. Manutenção Produtiva Total. 2.ed. São Paulo: Instituo IMAN, 2000.

TONDATO, R. Manutenção produtiva total: estudo de caso na indústria gráfica. Dissertação de Mestrado em Engenharia de Produção. Porto Alegre: Universidade Federal do Rio Grande do Sul, 2004.

SINGH, M.; SACHDEVA, A.; BHARDWAJ, A. An interpretive structural modelling approach for analysing barriers in total productive maintenance implementation. International Journal of Indústrial and Systems Engineering, v.16, n.4, p. 433-450, 2014.

YOSHICAZEM, O. Manutenção produtiva total. São Paulo: IMAN, 2002.

\section{Como Referenciar este Artigo, conforme ABNT:}

CAMARGO, J. S; RESENDE, A. A. Avaliação da TPM como Ferramenta de Melhoria no Desempenho da Produção: Um Estudo de Caso. Rev. FSA, Teresina, v.18, n. 04, art. 8, p. 144-158, abr. 2021.

\begin{tabular}{|l|c|c|}
\hline \multicolumn{1}{|c|}{ Contribuição dos Autores } & $\begin{array}{c}\text { J. S. } \\
\text { Camargo }\end{array}$ & $\begin{array}{c}\text { A. A. } \\
\text { Resende }\end{array}$ \\
\hline 1) concepção e planejamento. & $\mathrm{X}$ & $\mathrm{X}$ \\
\hline 2) análise e interpretação dos dados. & $\mathrm{X}$ & $\mathrm{X}$ \\
\hline 3) elaboração do rascunho ou na revisão crítica do conteúdo. & $\mathrm{X}$ & $\mathrm{X}$ \\
\hline 4) participação na aprovação da versão final do manuscrito. & $\mathrm{X}$ & $\mathrm{X}$ \\
\hline
\end{tabular}

